New Syllabus Mathematics for O-Level 2 
New Syllabus Mathematics for O-Level 2 


\title{
New Syllabus Mathematics for O-Level 2
}

\author{
Owen Perry, B.Sc.,
}

Head of Department of General and

Professional Studies,

Lewes Technical College

Joyce Perry, B.Sc.,

Formerly Mathematics Teacher,

Lewes High School 
(C) Owen Perry and Joyce Perry 1979

All rights reserved. No part of this publication may be reproduced or transmitted, in any form or by any means, without permission.

First published 1979 by

THE MACMILLAN PRESS LTD.

London and Basingstoke

Associated companies in Delhi Dublin

Hong Kong Johannesburg Lagos Melbourne

New York Singapore and Tokyo

\section{British Library Cataloguing in Publication Data}

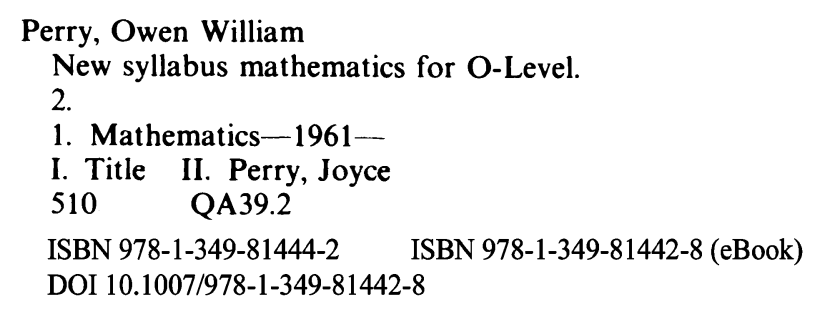

The paperback edition of this book is sold subject to the condition that it shall not, by way of trade or otherwise, be lent, resold, hired out, or otherwise circulated without the publisher's prior consent in any form of binding or cover other than that in which it is published and without a similar condition including this condition being imposed on the subsequent purchaser. 


\section{Contents}

Preface vii

Notation viii

1. Quadratic Functions 1

Polynomial functions. Factorisation of quadratic functions, quadratic equations and inequalities, solutions by factors, by formula and graphical methods. Simultaneous and fractional equations. Conditional equations and identities. Remainder theorem. Composition of quadratic functions.

\section{Trigonometry}

Sine, cosine, tangent, trigonometrical tables. Angles of elevation and depression. Solution of triangles, sine and cosine formulae, area formulae, ambiguous case. Functions of obtuse and reflex angles. Bearings. Graphs of $\sin \theta, \cos \theta, \tan \theta$. Graphical solution of trigonometrical equations.

3. Variation, Kinematics and Further Graphs

Direct, partial, inverse and joint variation. Obtaining a linear relationship from experimental data, use of logarithmic and exponential functions. Area by trapezium rule. Kinematics, time-distance, time-velocity graphs. Recognising and sketching curves of linear, quadratic, cubic, exponential and reciprocal functions.

\section{Coordinate Geometry and Calculus}

Distance between points, gradient of a line, angle between lines, equation of a line, dividing a line in a given ratio. Polar coordinates, conversion to Cartesian coordinates. Differential calculus. Derived function, differentiation of $x^{n}$ by formula, application to gradients and tangents, maxima and minima. Integral calculus. Indefinite and definite integrals, limits, area under a curve, volume of a solid of revolution. Kinematics. 
Vector and scalar quantities. Free vectors, position vectors, vector addition, the triangle law, negative, zero and unit vectors, multiplication by a scalar. Vectors in the Cartesian coordinate system, free vectors as matrices, relative vectors, magnitude of a vector, $\mathbf{i}$ and $\mathbf{j}$. Transformation of the Cartesian plane, translations, enlargement, shears, reflections, rotations. Combination of transformations. Representation by a matrix.

\section{Binary Operations, Finite Arithmetic and Groups}

Binary operations, operation tables, identity and inverse elements. Finite arithmetic modulo n. Groups, group tables, group axioms. Infinite and finite groups, isomorphic groups. Symmetry groups of plane figures, rotation groups of triangle, square, rhombus, regular polygon. Isometry groups of triangle and rhombus.

7. Further Plane Geometry

Theorems: $1-4$ lines, angles; 5-18 triangles; $19-21$ ratio theorems; $22-30$ circle theorems, 31 and 32 chord and tangent theorems. Loci.

\section{Geometry and Trigonometry in Three Dimensions}

Normal to a plane, distance of a point from a plane, angles between lines and planes, angle between planes, line of greatest slope. Latitude and longitude, nautical mile and knot. Plans and elevations, orthographic projections, first-angle and third-angle.

Answers to Exercises 


\section{Preface}

These two volumes are intended for students who want to pass O-Level mathematics in the modern syllabus. They are particularly suitable for those who need to follow a thorough revision course, whether at school or as fulltime, day-release or evening students at colleges of further education. Since the only mathematical knowledge assumed is simple arithmetic, the books are also suitable for those who need a pass in O-Level mathematics to improve their promotion prospects, and are starting the modern syllabus for the first time.

The majority of the exercises are divided into A and B sections. The questions in the $A$ sections are generally shorter and intended for routine practice in the techniques appropriate to each part of the text. Longer and more thought-provoking questions are found in the B sections. Each of the sixteen chapters ends with a multiple-choice test and a selection of miscellaneous examples from past examination papers.

The authors are grateful to Dr Patricia Dauncey, for her helpful criticism of the manuscript and for working through the exercises. They also wish to thank the Controller of H.M.S.O. for permissions to use Statistical Abstracts.

The text covers the 'modern' alternative syllabus of each of the major examining boards, and the authors acknowledge with thanks the permission given by these boards to quote examination questions. The source of each question is shown in the text by the following abbreviations
(AEB)
Associated Examining Board
(C)
University of Cambridge Local Examinations Syndicate
University of London, University Entrance and School
(JMB)
Examinations Council
(NI)
Joint Matriculation Board
(O)
Northern Ireland Schools Examinations Council
(OC SMP) Oxford and Cambridge Schools Examination Board.
Schools Mathematics Project
(S) Southern Universities Joint Board
(SCE) Scottish Certificate of Education Examination Board. 


\section{Notation}

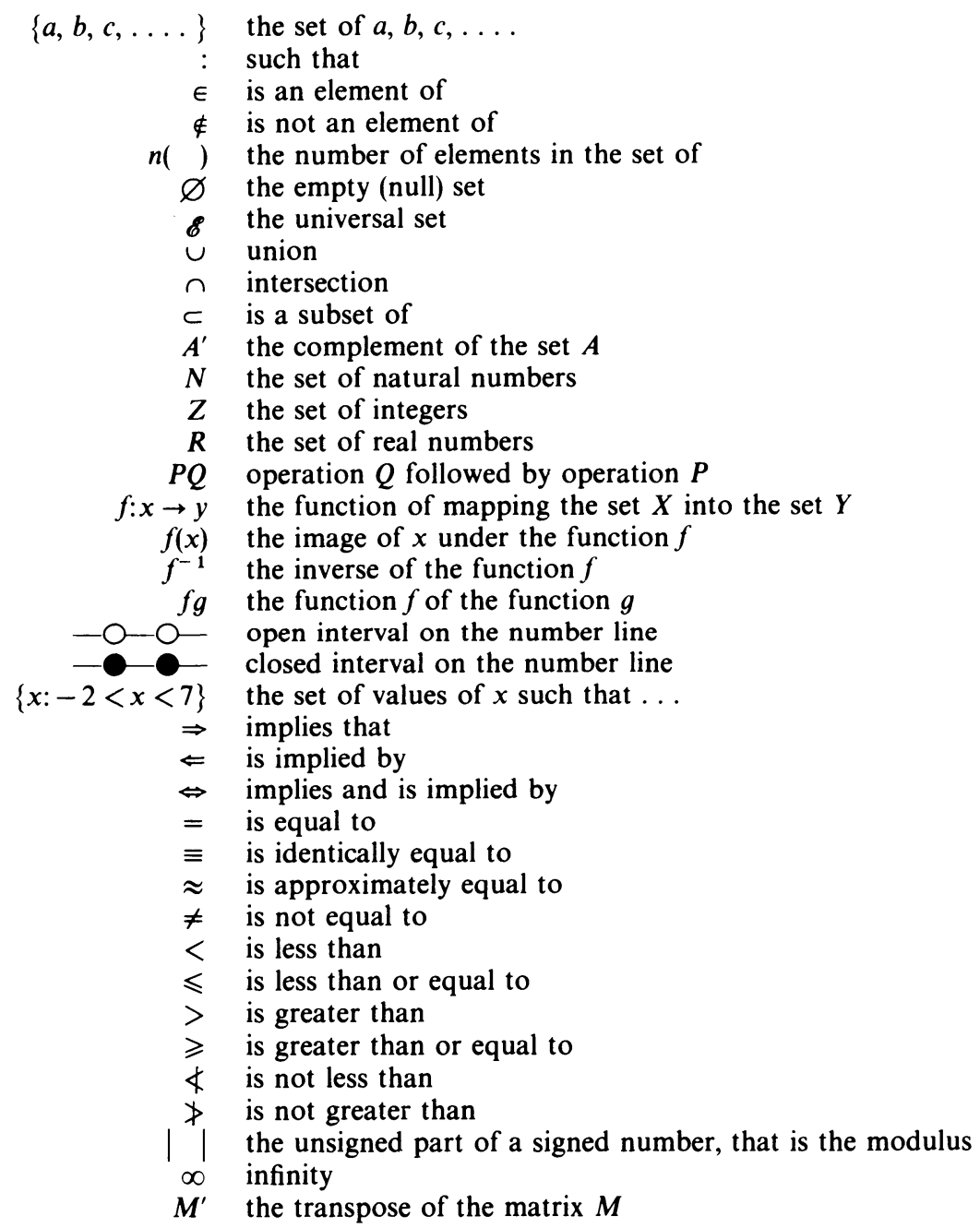

